\title{
The economics of union organization: Efficiency, information and profitability ${ }^{2}$
}

\author{
Pablo Ruiz-Verdú \\ Universidad Carlos III de Madrid, Departamento de Economia de la Empresa, \\ Calle Madrid, 126 Getafe - 28903, Madrid, Spain
}

\begin{abstract}
This article presents a game theoretical model of union organization that highlights the role played by efficiency and asymmetric information as determinants of unionization and questions commonly held assumptions about the effect of firm profitability on unionization decisions. In the model, employers set wages taking into account the effect of their choices on workers' incentives to unionize. As a result of employers' strategic wage setting, collective bargaining emerges in equilibrium only if it increases surplus or if there is asymmetric information about the consequences of unionization. While unionization is usually assumed to be more likely in more profitable firms, the model shows that the probability of unionization will be higher in firms with lower rents. It also shows that the union wage premium and unionization will tend to be negatively correlated.
\end{abstract}

JEL classification: J51; J41

Keywords: Unionization; Asymmetric information; Union efficiency; Profitability

\section{Introduction}

In countries with decentralized collective bargaining systems, such as the U.S. or Great Britain, collective bargaining takes place only if workers request to be represented by a trade union and the firm employing them agrees to bargain with one. Since we observe both union and

\footnotetext{
The author thanks Fabien Postel-Vinay and two anonymous referees for their extremely helpful comments. He would also like to thank Edward Lazear, Robert McMillan, John Pencavel, Steve Tadelis and Frederic Warzynski for insightful discussions. Any remaining errors are his own. The financial support of Spain's Ministry of Education and Science (SEJ2005-06655/ECON) is gratefully acknowledged.

E-mail address: pablo.ruiz@uc3m.es.
} 
nonunion firms, the challenge for the researcher is to explain why collective bargaining emerges in some firms and not in others. To address this question, this paper presents a model in which unionization is determined as the equilibrium outcome of the strategic interaction between a firm and its workers.

The prevalent view among economists is that unions' main role is to increase the wages of their members. Thus, it is often argued that unionization will be more likely in more profitable firms, since it is in those firms where the expected wage gains from unionization are larger. This argument, which focuses on workers' incentives to unionize, has been criticized on the grounds that greater expected wage gains will, other things equal, also strengthen firms' incentives to resist unionization (Freeman, 1986). Therefore, an alternative view stresses the costs of unionization to workers-especially those that stem from employers' actions-and casts doubt on the sign of the effect that profitability may have on unionization. Finally, a third view, while acknowledging unions' role in increasing the wages of their members, contends that unions play other roles that may be conducive to efficiency. Replacing individual contracting with collective contracting can economize in transaction costs and may lead to improved governance of the employment relationship for a variety of reasons (Freeman and Medoff, 1984; Williamson, 1985). Thus, a key determinant of unionization, according to this view, will be unions' potential to contribute to workplace efficiency.

This article presents a formal model of unionization that draws from these three views. In it, firms may differ in the rents that can be shared with workers; in the fraction of those rents that workers can appropriate by unionizing; in the costs of unionization for workers; and in whether unionization results in efficiency gains or losses. Therefore, the model allows us to assess the impact that firm profitability, the union wage premium and the effect of unions on efficiency will have on the probability of unionization.

The model has three key ingredients. The first one is strategic wage setting: when employers set wages, they take into account the effect of their choice on workers' incentives to unionize. Although present in prior analyses of the effect of unions on wages, strategic wage setting has often been overlooked in the discussion about the determinants of unionization. The second key feature of the model is that information about the consequences of unionization is allowed to be asymmetrically distributed between workers and their employer. While unorganized workers will have, at best, a noisy assessment of the firm's ability to generate rents and, thus, of their expected gains from unionization, the very nature of the managerial role involves acquiring and processing information about the firm's current state and future prospects, and the manager's actions-some of which are unobservable to workers-largely determine those prospects. Therefore, the model also analyzes unionization when the employer is better informed than workers about the firm's prospects. Finally, reflecting the lack of agreement about the efficiency effects of unions, unions are allowed to have either a positive or a negative effect on surplus.

The model shows that if workers and their employer have the same information about the benefits and costs of unionization, the only determinants of unionization will be the union's effect on efficiency and the costs of organization to workers: unionization takes place in equilibrium if and only if it generates efficiency gains that exceed the organization costs. As long as unionization is potentially profitable for workers, other factors such as the firm's profitability or the union's bargaining strength will not play any role in determining unionization.

Results change greatly once asymmetries of information are considered. First, asymmetric information allows unionization to take place even if it is inefficient, and may preclude union formation when it is efficient. And, second, if unionization is inefficient, it will be more likely in firms with worse prospects. This result questions the commonly-held assumption that 
unionization will be more likely where rents are larger: although the presence of quasi-rents is necessary for unionization to be possible, the model predicts that firms with larger quasi-rents are less likely to become unionized. These results also have important consequences for the empirical research on the impact of unionization on wages and firm performance. One of the main obstacles faced by this strand of research is that union and nonunion firms may be different in dimensions other than their union status. If not accounted for, these differences may result in biased estimates of the effects of unionization. Since unionization is generally assumed in empirical work to be more likely in more profitable firms or in firms that would in any case pay high wages, it is often argued that the negative effect of unions on profits that is usually found is underestimated and that the union wage premium is overestimated. The model presented here shows that biases due to unobserved differences between union and nonunion firms are likely to emerge. It also shows that they may have the opposite sign to the one that is usually hypothesized in empirical work.

The model also allows us to analyze the relationship between the probability of unionization and the union wage premium. While a demand-driven explanation of unionization would imply that unionization is more likely when the union wage premium is high, the view that focuses on employers' resistance to unionization could yield the opposite prediction. In this paper, both unionization and the wage premium are determined in equilibrium, and they are shown to move in opposite directions as the values of other parameters change. Thus, the model predicts a negative correlation between the two variables.

Although there are very few formal models of unionization, reduced-form models are often used in empirical work to guide in the specification of estimating equations. In studies using aggregate data, estimating equations for the extent of unionization are often interpreted as equilibrium equations of a market of union services, while when worker-level data are used, the union status of workers is usually supposed to depend on workers' demand for union jobs and on their ability to find them, although the two factors are rarely identified separately (Farber, 1990). More closely related to the concerns of the present article are studies that focus on the determinants of unionization at the firm level. These studies typically assume a function that relates employers' actions (such as wages, Farber, 2005; or anti-union activities, Freeman and Kleiner, 1990a) to the probability of unionization. There are, however, few instances in which unionization is explicitly derived from the optimizing behavior of employers and workers. Lazear (1983) provided a model in which unionization and wages were determined simultaneously in equilibrium. In his model, workers announce an industry-wide wage demand, and employers decide whether to accept that demand or to reject it at a cost. The model thus provides a better description of a unionized industry with centralized bargaining, in which employers can deviate from the collective bargaining agreement at a cost, than of an industry with either no or decentralized bargaining, in which unorganized workers decide at the firm level whether or not to unionize. Horn and Wolinsky (1988) developed a model in which the structure of collective bargaining was determined in equilibrium and was shown to depend upon technological parameters. Although their focus was on the choice between encompassing unions versus separate unions for different types of workers, their model can also be interpreted as providing conditions under which individual or collective bargaining is optimal for workers. Apart from the work of Lazear (1983) and Horn and Wolinsky (1988), a series of papers (Booth, 1985; Naylor and Cripps, 1993; Naylor and Raaum, 1993; Corneo, 1995) has developed theoretical models of union membership that analyze the free-riding problem that arises when workers can benefit from the wage increases bargained by the union without becoming members. Although related to the present paper in their goal to explicitly model unionization decisions at the firm level, the focus of these articles is different in that they typically assume the existence of union-management 
bargaining and try to explain individual membership decisions given that all workers receive the wages negotiated by the union. These papers, which, in some cases (Naylor and Raaum, 1993; Corneo, 1995), allow for an active role of management opposing union membership, have stressed the role of social custom as the solution to the free-riding problem. More closely related to the approach of the present paper is an article by Corneo and Lucifora (1997), where the authors present a game-theoretical model in which a local union with a predetermined level of membership must decide whether to conduct local wage negotiations, and the employer makes a wage offer taking into account that a low wage may lead the union to press for wage bargaining. The model presented here differs from the literature on the free-riding problem in that its starting point is a situation in which there is no collective bargaining or union presence and its goal is, precisely, to explain the conditions under which collective bargaining will emerge.

The plan of the paper is as follows. Section 2 presents the model, Section 3 solves it when there is complete information, and Section 4 analyzes the consequences of the existence of informational asymmetries. Finally, Section 5 analyzes the model's implications and the available empirical evidence, and Section 6 concludes.

\section{The model}

Consider a firm that lives for two periods. In the first period, the firm offers a wage $w_{0}$ to a pool of identical workers who can obtain a wage $w$ outside the firm. If workers accept the wage offer, production takes place, workers acquire firm-specific skills through on-the-job learning, and revenues $V_{0}$ are generated; otherwise, the firm closes and obtains zero revenues. I assume, for simplicity, that the firm has a fixed number of jobs and that, if production takes place, all the jobs are filled.

At the beginning of the second period, the firm offers a wage $w$ to its employees, who can: i) accept the offered wage, ii) form a union to renegotiate the wage, or iii) leave the firm and earn $w$. If workers accept the offer, they are paid $w$ and generate revenues $V$; if they form a union, they incur organization costs per worker $c$, and collective bargaining takes place, resulting in revenues $V^{u}$ and a union wage $w^{u}$. Finally, if workers leave the firm, alternative workers are hired. These workers are paid their reservation wage $w$ and generate revenues $V$. Since alternative workers lack the firm-specific skills of incumbents, $V<V$. I will denote by $W$ and $W^{u}$ the total wage bills if workers accept the wage offer and if they unionize, respectively. Analogously, $C$ will denote total organization costs for workers. For the sake of notational simplicity-and without loss of generality-I will assume throughout the paper that $w=V=0$.

It will also be assumed that there is no time discounting. The timing of events is depicted in Fig. 1. Below, I discuss some of the model's assumptions in greater detail.

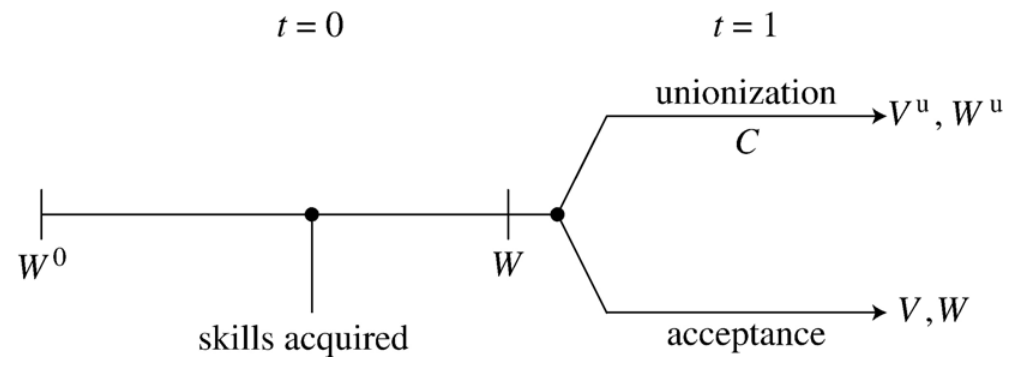

Fig. 1. Time-line. 


\subsection{Union organization}

It is assumed that workers are initially unorganized, but that they can unionize at a $\operatorname{cost} C$. Both assumptions reflect the institutional framework of countries like the U.S. or Great Britain, in which, on the one hand, there is no mandate for firms to set up any sort of body representing workers, while, on the other hand, firms are obliged to recognize and bargain with a union if a majority of workers express their will to be represented by one. Employers' obligation to recognize a union, however, does not imply that the process of unionization is costless for workers. Before a majority of workers can voice their wish to obtain union representation, at least some workers need to acquire information about the process governing union recognition and the potential costs and benefits that would stem from it; this information needs to be shared with coworkers and some form of consultation is required to assess the interests of the majority. All these activities are costly and subject to potentially severe free-riding problems (Booth, 1985; Corneo, 1995). Moreover, they can be made more costly by employers by legal means (like, say, appealing union recognition decisions) or illegal ones, such as discharging employees supportive of unionization. Even if some of the organizing activities can be carried out by an established union, the costs incurred would still be ultimately borne by workers in terms of initiation fees and union dues. The actual process by which workers acquire union representation is, thus, complex, and is beyond the scope of this paper to model it. For the purposes of this paper, what matters is that unionization entails costs for workers and that workers take into account these costs when they decide whether to unionize.

\subsection{Bargaining}

Because of the firm-specific skills acquired by workers in the first period, the revenues that the firm can obtain in the second period if it employs incumbent workers are larger than those that could be obtained by hiring alternative workers. ${ }^{1}$ Therefore, workers can attempt to bargain with the firm for a share of the quasi-rents that result from their firm-specific skills. Given the simplifying assumption that both $V$ and $w$ are zero, the size of these quasi-rents is simply $V$, so I will use the terms quasi-rents, revenues, or value interchangeably to refer to $V$. The model assumes that bargaining is possible only if workers negotiate collectively with management. This is a simplifying assumption: all that is needed is that workers' bargaining power is greater if they bargain collectively.

If unionization takes place, the union and management bargain over the wage. While different bargaining models would generate different predictions about $V^{u}$ and $w^{u}$, it is not necessary for our purposes to commit to a particular model of union-management bargaining. When workers decide whether to unionize or when the firm decides what wage to offer, all that matters to them is the expected outcomes of the bargaining process: $w^{u}$ and $V^{u}$. Therefore, instead of modelling how these variables are determined, I take them as parameters and impose the mildest possible restrictions on the values that they can take. Hence, the model's results apply to any bargaining model whose outcomes satisfy those restrictions. Note also that we do not have to make any specific assumptions about the objectives of the union officials who bargain with management if the union forms. The impact of those objectives on the bargaining outcome is already incorporated in $w^{u}$.

\footnotetext{
${ }^{1}$ Firm-specific skills do not play any role in the model other than ensuring that incumbent employees are more valuable than outsiders. Any other sort of firing or hiring costs would yield the same implications.
} 


\subsection{Unionization and efficiency}

Standard models of union-management bargaining predict that $V^{u}-V$ is either negative (if collective bargaining leads to inefficient input choices, as in so-called "monopoly union" or "right-to-manage" models) or zero ("efficient bargaining" models). ${ }^{2}$ It has long been argued, however, that there are different ways in which unions may improve efficiency. For example, collective contracting through the union may economize in contracting costs and lead to better decisions regarding many aspects of workplace organization that have a public good nature (e.g., working conditions, pension plans). ${ }^{3}$ The empirical evidence on the efficiency effects of unionswhich has focused mostly on productivity-is, however, not conclusive. Reflecting the lack of consensus about the effects of unionization on efficiency, in the model, the difference $V-\left(V^{u}-C\right)$ is allowed to be positive, negative or zero, although the case $V-\left(V^{u}-C\right)>0$ will receive special attention when the effects of asymmetric information are considered.

\subsection{Other simplifying assumptions}

Employment is assumed to be fixed in the model. Since it is plausible-and predicted by some of the most commonly used collective bargaining models-that unionization may affect employment, I discuss the consequences of relaxing this assumption in Section 3. For tractability, it is also assumed that workers are identical and are treated identically by the firm and, in case of unionization, by the union.

\section{Efficient unionization}

When setting the second period wage, employers will take into account how this wage affects workers' incentives to unionize. If there is perfect information about the bargaining outcome that would result if workers unionized, so that workers know that their net payoff from unionization is $W^{u}-C$, unionization will take place unless $W \geq W^{u}-C$. Since employers set $W$, unionization will thus occur only if paying $W^{u}-C$ is more costly to the employer than allowing unionization and incurring wage costs $W^{u}$. As long as $C \geq 0$, this can only happen if unions increase value. Proposition 1 states this result (all proofs are in the appendix). It is worth noting that firms in which $W^{u}-C<0$ are not unionizable, in the sense that workers would never unionize independently of the wage offer made by the firm. In what follows, I will, unless otherwise noticed, restrict attention to unionizable firms, that is, those with $W^{u}-C>0$.

Proposition 1. Suppose that $W^{u}$ is observed both by workers and by the employer. Then:

1. If $V^{u}-V<C$, at the unique subgame perfect equilibrium, the firm offers $W_{0}^{*}=-\left(W^{u}-C\right)$ and $W^{*}=W^{u}-C$, and workers accept the wage offers on the equilibrium path.

2. If $V^{u}-V>C$, at any subgame perfect equilibrium, the firm offers $W_{0}^{* *}=-\left(W^{u}-C\right)$, $W^{* *} \leq W^{u}-C$, and workers unionize.

It has long been argued (Freeman and Medoff, 1984; Williamson, 1985) that the effect of unions on workplace efficiency may be an important factor determining unionization. Proposition

\footnotetext{
${ }^{2}$ See Booth (1995), chapters 4 and 5, for a review of the main collective bargaining models.

${ }^{3}$ Freeman and Medoff (1984) and Booth (1995) provide discussions of the potential efficiency effects of unions and the empirical evidence on those effects.
} 
1 shows that, in the absence of informational asymmetries, efficiency and the costs of organization to workers are the only factors determining unionization. This is a strong result in two respects. First, it shows that unions will appear only where they are efficient: unionization will not take place where it would destroy value or merely redistribute surplus from firm owners to workers. Since usual theoretical models of collective bargaining predict no or a negative effect of unions on efficiency, this result implies that no unionization would take place under the assumptions made by those models. The result is also strong in that it implies that factors other than unions' impact on efficiency, such as the firm's revenues or the union's bargaining power, do not have a direct causal effect on the probability of unionization among unionizable firms. These factors will be correlated with unionization only insofar they are associated with unions' ability to generate efficiency gains or with the costs of organization to workers.

Throughout the paper, it is assumed for simplicity that the level of employment is fixed. The logic behind Proposition 1-namely, that it is cheaper for employers to pay workers to dissuade them from unionizing than letting unionization happen as long as unions do not increase surplusstill applies if we relax this assumption. To see this, suppose that unionization led to a level of employment $L^{u}$ lower than the initial one, $L$. This would translate into lower revenues if the union forms $\left(V^{u}<V\right)$ and would imply that only a proportion $L^{u} / L$ of workers stays at the firm and earns the union wage. Assuming that all workers have the same probability of being laid off in case of unionization and letting $c$ represent the per worker cost of organization, workers' expected utility from unionization would be $\frac{W_{u}}{L}-c .{ }^{4}$ Therefore, the firm could avoid unionization if it set a wage $w=\frac{W_{u}}{L} c$, that is, if its total wage costs were $L\left(\frac{W_{u}}{L} c\right) W^{u} C$. It follows that the firm can earn $V-W^{u}+C$ if it avoids unionization and $V^{u}-W^{u}$ if a union forms, which brings us back to the analysis in Proposition 1.

It is also worth noting that Proposition 1 implies that the first-period wage is negative. This result is, in part, an artifact of the assumptions that $w=0$ and that there is no time discounting. More importantly, whether or not the firm can recover through a low $w_{0}$ the rents that it has to grant workers in the second period is immaterial for the results. Since the first period plays no significant role in the analysis, I will omit it from the discussion hereafter.

\section{Asymmetric information and inefficient unionization}

As argued in the introduction, it is reasonable to expect that management will have better information than workers about the firm's prospects. This section analyzes the impact of this asymmetry of information on unionization decisions. ${ }^{5}$ To do this, the information structure is now as follows. In the first period, workers and management know that the firm can generate revenues $V_{0}$ and have the same information about the revenues that a skilled worker would generate in the second period. In particular, it is known that firms can be either high-value $(H)$ or low-value $(L)$, with second-period revenues given by $V_{H}>V_{L}$ and $V_{H}^{u}>V_{L}^{u}$. The wage bills that would result from unionization in each type of firm, $W_{H}^{u}>W_{L}^{u}$, are also commonly known. Finally, workers and firms know the true distribution of types, given by $q$, the probability that a firm is high-value.

At the beginning of the second period, after workers have accumulated firm-specific human capital, management learns the firm's type and makes a new wage offer to the employed workers.

\footnotetext{
${ }^{4}$ For simplicity, it was assumed that $w \quad 0$, so workers' expected utility from unionization is $w_{u} \frac{L^{u}}{L}+\bar{w}\left(1 \frac{L^{u}}{L}\right) c \quad \frac{W_{u}}{L} c$.

${ }^{5}$ The relevance of asymmetric information in unionized settings has been previously highlighted by theoretical models of strikes (see Kennan and Wilson, 1993, for a review).
} 
Workers then decide whether to accept the wage offer or to organize a union. If a union forms, union officials are able to observe the firm's type, so the negotiated wage is $W_{H}^{u}$ in high-value firms and $W_{L}^{u}$ in low-value firms. Specialized union officials have the time and skill to investigate the firm's prospects, so it is natural to assume that they have better information than unorganized workers. The assumption that their information is as good as management's is made for simplicity. The results would not change in any qualitative form if it were assumed, instead, that the union has the same information as unorganized workers, that it observes an additional noisy signal, or that some information is revealed in the course of bargaining. Fig. 2 depicts the timing of events when there is asymmetric information.

In what follows, I will consider only equilibria in which firms play pure strategies. Considering equilibria in which firms randomize between different wage offers increases the number of equilibria, but the additional equilibria do not exhibit features different from those displayed by pure strategy equilibria nor provide new insights. The probability with which workers organize if the wage $W$ is offered (that is, workers' behavior strategy in the second period) will be denoted by $\sigma(W)$, and $\rho(W)$ will denote the probability workers assign to the firm being high-value, given that a wage $W$ has been offered. Thus, $\rho$ represents workers' beliefs about the relationship between wage offers and firm types. The equilibrium concept will be the perfect Bayesian equilibrium (see Fudenberg and Tirole, 1991, page 325):

Definition 1. A perfect Bayesian equilibrium (PBE) is a strategy profile $\left(\sigma^{*},\left(W_{L}^{*}, W_{H}^{*}\right)\right)$ and posterior beliefs by workers $\rho^{*}$ such that:

D.1. For all $W, \sigma^{*}(W) \in \arg \max _{\sigma} \sigma\left[\rho^{*}(W) W_{H}^{u}+\left(1-\rho^{*}(W)\right) W_{L}^{u}-C\right]+(1-\sigma) W$.

D.2. $W_{i}^{*} \in \arg \max _{W} \sigma^{*}(W)\left(V_{i}^{u}-W_{i}^{u}\right)+\left(1-\sigma^{*}(W)\right)\left(V_{i}-W\right)$, for $i=L, H$.

D.3. $\rho^{*}(W)=q$ if $W=W_{L}^{*}=W_{H}^{*} ; \rho^{*}(W)=1$ if $W=W_{H}^{*} \neq W_{L}^{*} ; \rho^{*}(W)=0$ if $W=W_{L}^{*} \neq W_{H}^{*}$; and $\rho^{*}(W) \in[0,1]$, otherwise.

The first two conditions require workers and the firm to play best responses to each other's strategy. The third condition requires workers' beliefs to be derived from the prior distribution and from the firm's equilibrium strategy using Bayes' rule whenever possible (that is, whenever a wage is set by at least one type of firm in equilibrium).

\subsection{Inefficient unionization}

Under complete information, unionization does not take place if it is inefficient. Given the lack of conclusive evidence of a positive and substantial impact of unionization on efficiency and the

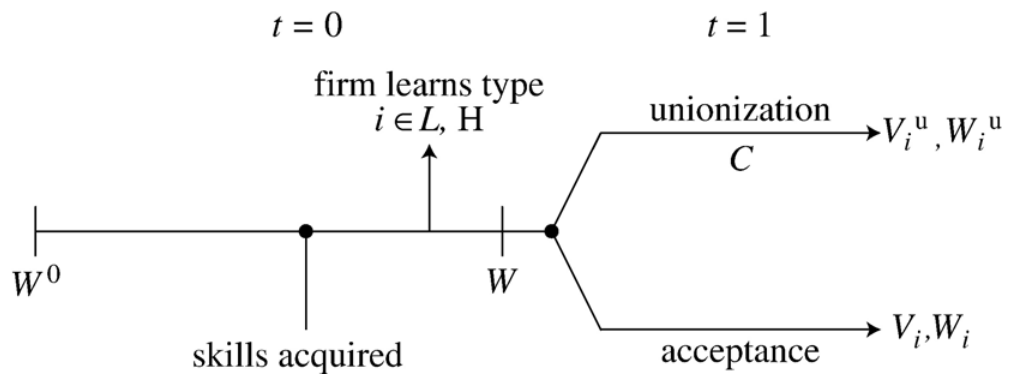

Fig. 2. Time-line. Asymmetric information. 
fact that usual bargaining models predict no or a negative effect on efficiency, this subsection investigates whether asymmetric information can result in inefficient unionization. Throughout this subsection, it will thus be assumed that:

Assumption AS.1. $V_{i}^{u}-V_{i}<C$ for $i=L, H$.

To see how asymmetric information may alter the results of Section 3, first note that if no information is credibly communicated to workers, they will unionize unless they are offered a wage greater or equal to the ex ante expected wage from unionization net of organization costs, $W_{L}^{u}+q\left(W_{H}^{u}-W_{L}^{u}\right)-C$. This expected wage is greater than the wage that would allow a low-value firm to avoid unionization if workers knew its type. Therefore, low-value firms would like to reveal their low value to workers. However, they cannot credibly do so while at the same time avoiding organization, since, in that case, it would be optimal for high-value firms to imitate them. Therefore, if the ex ante expected wage from organization is high enough, so that avoiding unionization becomes too costly, the only alternative for low-value firms is to trigger organization, thus revealing their type to the union. Proposition 2 below shows that this intuitive argument is correct if the following assumption holds:

Assumption AS.2. $V_{H}-V_{H}^{u}+W_{H}^{u}>V_{L}-V_{L}^{u}+W_{L}^{u}$.

For a firm of type $i$ that is paying a wage $W$, the cost of unionization is $\left(V_{i}-W\right)-\left(V_{i}^{u}-W_{i}^{u}\right)$. Therefore, AS.2 states that unionization is more costly for high-value firms. If unions do not have any efficiency effects, AS.2 simply amounts to $W_{H}^{u}>W_{L}^{u}$. If unions have a negative impact on efficiency, AS.2 only requires that this impact is not significantly larger in low-value firms.

Proposition 2. Suppose that AS.1 and AS.2 hold. Then,

1. There exist separating equilibria.

2. In any separating equilibrium: $W_{H}^{*}=W_{H}^{u}-C ; W_{L}^{*} \leq W_{L}^{u}-C ; \sigma^{*}\left(W_{H}^{*}\right)=0, \sigma^{*}\left(W_{L}^{*}\right)=1$ if $W_{L}^{*}<W_{L}^{u}-C$ and $\sigma^{*}\left(W_{L}^{*}\right) \in[\sigma, \min \{1, \sigma\}]$ if $W_{L}^{*}=W_{L}^{u}-C$, where:

$$
\sigma \equiv \frac{W_{H}^{u}-W_{L}^{u}}{V_{H}-V_{H}^{u}+C+W_{H}^{u}-W_{L}^{u}}>0 \sigma \equiv \frac{W_{H}^{u}-W_{L}^{u}}{V_{L}-V_{L}^{u}+C}
$$

If AS.2 does not hold, then there are no separating equilibria.

Several remarks about Proposition 2 are in order. First, separation is possible in equilibrium because AS.2 ensures that unionization is more costly for high-value firms and, thus, that they are willing to pay more to avoid it. Second, high-value firms set the same wage as in the complete information case and avoid unionization with certainty. Third, if $W_{H}^{u}-W_{L}^{u}<V_{L}-V_{L}^{u}+C$, then $\sigma^{*}\left(W_{L}^{*}\right)<1$, and there are no equilibria with $W_{L}^{*}<W_{L}^{u}-C$. However, if $W_{H}^{u}-W_{L}^{u} \geq V_{L}-V_{L}^{u}+C$, then $\sigma \geq 1$, so there are equilibria with $W_{L}^{*}=W_{L}^{u}-C$ and $\sigma^{*}\left(W_{L}^{*}\right)=1$. In this case, there are also equilibria with $W_{L}^{*}<W_{L}^{u}-C$, which necessarily require $\sigma^{*}\left(W_{L}^{*}\right)=1$. $^{6}$ Finally, the beliefs supporting the equilibria are plausible and immune to the Intuitive Criterion, which is the most common refinement of the perfect Bayesian equilibrium in signaling contexts.

Although separating equilibria like the ones described in Proposition 2 will exist whenever AS.2 holds, if the ex ante expected union wage is relatively low and the revenue loss from union-

\footnotetext{
${ }^{6}$ Note that $W_{H}^{u}-W_{L}^{u} \geq V_{L}-V_{L}^{u}+C$ can be rewritten as $W_{H}^{*} \geq W_{L}^{*}+V_{L}-V_{L}^{u} \equiv \widehat{W}_{L}$, where $\widehat{W}_{L}$ is the wage that guarantees low-value firms a level of profits $V_{L}^{u}-W_{L}^{u}$ independently of workers' decision. Thus, if $W_{H}^{*} \geq \widehat{W}$, low-value firms prefer unionization to paying $W_{H}^{*}$.
} 
ization for low-value firms is relatively high, there will also exist equilibria in which low- and high-value firms set the same wage and avoid unionization with positive probability. Proposition 3 describes these pooling equilibria:

Proposition 3. Suppose that AS.1 holds. Then

1. If AS.2 holds, then there exist pooling equilibria if and only if

$$
V_{L}-\left(q W_{H}^{u}+(1-q) W_{L}^{u}-C\right) \geq V_{L}^{u}-W_{L}^{u},
$$

At these equilibria: $W_{H}^{*}=W_{L}^{*}=W_{p}^{*} \geq W_{p}, \sigma^{*}\left(W_{p}^{*}\right)=0$ if $W_{p}^{*}>W_{p}$, and $\sigma^{*}\left(W_{p}^{*}\right) \leq \sigma_{1}$ if $W_{p}^{*}=W_{p}$, where $W_{p} \equiv q W_{H}^{u}+(1-q) W_{L}^{u}-C$, and

$$
\sigma_{1} \equiv \frac{(1-q)\left(W_{H}^{u}-W_{L}^{u}\right)}{(1-q)\left(W_{H}^{u}-W_{L}^{u}\right)+V_{H}-V_{H}^{u}+C}
$$

2. If AS.2 does not hold, then there always exist pooling equilibria with $W_{H}^{*}=W_{L}^{*}=W_{p}^{*} \geq W_{p}$, $\sigma^{*}\left(W_{p}^{*}\right)=0$ if $W_{p}^{*}>W_{p}$, and $\sigma^{*}\left(W_{p}^{*}\right) \leq \sigma_{2}$ if $W_{p}^{*}=W_{p}$, where

$$
\sigma_{2} \equiv \frac{(1-q)\left(W_{H}^{u}-W_{L}^{u}\right)}{(1-q)\left(W_{H}^{u}-W_{L}^{u}\right)+V_{L}-V_{L}^{u}+C}
$$

Note that condition (1) simply states that low-value firms prefer to pay the ex ante expected wage than to become unionized with certainty. If it holds, then, there exist pooling equilibria.

At these equilibria, low-value firms pay a wage higher than $W_{L}^{u}-C$ in exchange for a low probability of unionization, and high-value firms take the risk of becoming unionized (when $\sigma^{*}\left(W_{p}^{*}\right)>0$ ) in exchange for a low wage. It is worth noting that whenever pooling equilibria exist, there are pooling equilibria in which unionization is avoided with certainty.

I argued above that it is reasonable to expect AS.2 to hold. For completeness, Propositions 2 and 3 also describe what would happen if AS.2 did not hold, that is, if unionization were more costly in low-value firms. On the one hand, Proposition 2 shows that if AS.2 does not hold, there are no separating equilibria, since it is always better for low-value firms to pay $W_{H}^{u}-C$ than to allow unionization. This implies that there are no parameter values for which unionization is more likely in high-value firms. On the other hand, Proposition 3 shows that if AS.2 does not hold (which implies that (1) must hold), then there exist pooling equilibria.

\subsection{Comparative statics}

Propositions 2 and 3 show that in any possible equilibrium, either the probability of unionization is the same in both types of firms (pooling equilibria), or it is higher in low-value firms (separating equilibria). The following corollary summarizes these results:

Corollary 1. In any equilibrium, the probability of unionization in low value firms is greater or equal than the probability of unionization in high value firms.

I analyze next how variables other than rents influence the probability of organization. Given the multiplicity of equilibria, to derive comparative statics results, I will assume that for

\footnotetext{
${ }^{7}$ While pooling equilibria with $W_{p}^{*} \bar{W}_{p}$ can be supported by plausible beliefs, equilibria with $W_{p}^{*}>\bar{W}_{p}$ require workers to interpret wages that are lower than the equilibrium one as being more likely to be offered by high-value firms, which may be an undesirable property.
} 
any vector of parameter values, workers and the firm coordinate on the equilibria that have the minimum probability of unionization. In other words, players coordinate on those equilibria that, given AS.1, maximize rents. Therefore, it will be assumed that pooling equilibria with $\sigma\left(W_{p}^{*}\right)=0$ are played whenever pooling equilibria exist, and separating equilibria with $\sigma\left(W_{L}\right)=$ $\sigma$ are played otherwise. It follows that the ex ante probability of unionization will be 0 if there are pooling equilibria and $(1-q) \sigma$ if there are no pooling equilibria. Inspection of Proposition 2 shows that $\sigma$ is decreasing in $C$ and $\left(V_{H}-V_{H}^{u}\right)$, and increasing in $\left(W^{u}-W_{L}^{u}\right)$. Further, inspection of AS.2 and condition (1) shows that reductions in $C$ or $\left(V_{L}-V_{L}^{u}\right)$ and increases in $\left(W_{H}^{u}-W_{H}^{u}\right)$ make pooling equilibria more likely. ${ }^{8}$ Therefore, we obtain the following corollary of Propositions 2 and 3:

\section{Corollary 2. The probability of organization is:}

\section{i. nondecreasing in $\left(W_{H}^{u}-W_{H}^{u}\right)$}

ii. nonincreasing in $C,\left(V_{L}-V_{L}^{u}\right),\left(V_{H}-V_{H}^{u}\right)$

Corollary 2 states, expectedly, that as organization costs or the efficiency losses due to unionization increase, unionization becomes less likely. It also states that as the difference between high- and low-value firms, as measured by $\left(W_{H}^{u}-W_{L}^{u}\right)$, widens, the probability of unionization increases. This is so for two reasons. On the one hand, it becomes more costly for low-value firms to pay wage $\bar{W}_{p}$, making pooling equilibria less likely. On the other hand, it makes it more profitable for high-value firms to imitate low-value ones when there is separation. It follows that, to avoid imitation by high-value firms, the probability of unionization of low-value firms in separating equilibria has to be higher.

It is worth remarking that restricting our attention to efficient equilibria simplifies the analysis, but does not bias the results. Although the analysis is more cumbersome and less precise, comparative statics can be performed without restricting the set of equilibria, and the conclusions of Corollary 2 remain essentially unchanged. ${ }^{9}$

\subsection{Union efficiency, firm value, and unionization}

In the absence of a priori reasons to expect the sign of the effect of unions on efficiency to be different in low- and high-value firms, the analysis of the impact of asymmetric information on unionization has focused on the case in which this sign is independent of firm profitability. Further, the sign of the effect has been assumed to be negative because of theoretical and empirical arguments pointing at a negative or, at best, positive yet minor impact of unionization on efficiency. For completeness, I briefly analyze here the effect that asymmetric information would have on unionization both in the case in which unionization

\footnotetext{
${ }^{8}$ Changes in $\left(V_{H}-V_{H}^{u}\right)$ affect condition AS.2. However, if (1) holds, then pooling equilibria will exist, independently of the value of $\left(V_{H}-V_{H}^{u}\right)$, as long as AS.1 holds. On the other hand, if (1) does not hold, then AS.2 must obtain, so that no pooling equilibria exist, independently of the value of $\left(V_{H}-V_{H}^{u}\right)$.

${ }^{9}$ I have chosen efficiency as an equilibrium selection criterion mainly for the sake of brevity and expositional simplicity. Equilibrium uniqueness, however, can also be achieved by means of a belief-based equilibrium refinement like the D1 criterion (a refinement stricter than the Intuitive Criterion see Fudenberg and Tirole, 1991, ch. 11). Applying this refinement, separating equilibria with $\sigma\left(W_{L}\right) \quad \sigma$ are selected whenever AS.2 holds, and pooling equilibria with $\sigma^{*}\left(W_{p}^{*}\right) \quad 0$ are selected otherwise. It can be readily seen that the sign of the comparative statics results would remain unchanged if this refinement were used. I would gladly provide these results upon request. They can also be found at http://www. pabloruizverdu.com/labour technical note.pdf.
} 
is efficient in all firms and in the asymmetric cases in which unionization is efficient in only one type of firm.

If unionization is efficient in both types of firms or only in low-value firms, results are identical to those that would be obtained under complete information: if unionization is efficient in all firms, unionization takes place in all with probability one; if unionization is efficient only in lowvalue firms, in equilibrium these firms become unionized with probability one, and high-value firms avoid unionization with certainty. To see why, notice that whenever unionization is efficient in low-value firms, these firms prefer unionization to paying a wage greater than $W_{L}^{u}-C$ and remaining nonunion. Therefore, in any possible equilibrium, it has to be the case that $\sigma\left(W_{L}\right)=1$. Thus, if high-value firms set $W_{H}=W_{L}$, they become unionized with probability one, and if they set $W_{H} \neq W_{L}$, they reveal their type. In the latter case, they avoid unionization only if $W_{H} \geq W_{H}^{u}-C$. If unionization is inefficient in high-value firms, they prefer to set $W_{H}^{u}-C$ and avoid unionization. If, on the contrary, unionization is efficient in high-value firms, these firms prefer to trigger unionization than to pay workers $W_{H}^{u}-C$ to avoid it.

Asymmetric information causes a departure from the complete information predictions only if unionization is efficient in high-value firms but not in low-value firms. In this case, under complete information, unionization would take place in high-value firms but not in low-value firms. With asymmetric information, however, there typically exist pooling equilibria in which the probability of unionization is the same for both types of firms. Although a full analysis is omitted for the sake of brevity, if the pooling wage is low enough, high-value firms do not want to deviate and trigger unionization despite the increase in value that unionization could generate, and low-value firms are not able to signal their type credibly without inducing unionization. Therefore, a modified version of Corollary 2 would hold in this case: asymmetric information makes the probability of unionization of low-value firms higher and the probability of unionization of high-value firms lower than their respective values under complete information. It is interesting to note that, since pooling equilibria may involve a positive probability of unionization, inefficiencies may emerge both because there is too much (inefficient) unionization of low-value firms and because there is too little (efficient) unionization of high-value firms.

\section{Implications}

\subsection{Determinants of unionization}

The model analyzed in the previous sections yields the following predictions about the determinants of unionization:

\subsubsection{Unions' impact on efficiency}

Proposition 1 states that, under complete information, unionization will take place if and only if it yields a net efficiency gain. Under asymmetric information, inefficient unionization is possible, but, as Corollary 2 shows, unionization is more likely the smaller its negative effect on value. Therefore, unionization will be more likely the greater (smaller) the positive (negative) efficiency effect of unionization.

\subsubsection{Costs of unionization to workers}

The other main determinant of unionization is the costs of organization to workers. As expected, the greater these costs, the cheaper it is for firms to avoid unionization and, thus, the less likely it is that workers organize. 


\subsubsection{Profitability}

As discussed in the introduction, firm profitability is often taken as a key determinant of unionization. If we let $E V \equiv q V_{H}+(1-q) V_{L}$ denote the expected revenues of a group of ex ante identical firms (with $E V=V$ in the complete information case), and we compare two groups of firms, $A$ and $B$, the model implies that the knowledge that $E V_{A}>E V_{B}$ does not allow us to predict that unionization will be more likely in $A$. Corollary 2, however, shows that, among firms that appear ex ante identical to workers, unionization will be more likely in those with lower revenues. Therefore, we should observe ex post a negative relationship between unionization and revenues among ex ante identical firms (which have the same $E V$ ).

There is, however, a caveat to the prediction that the probability of unionization should be either constant or decreasing in the level of revenues. Throughout the paper, it has been assumed that firms are unionizable in the sense that workers may possibly gain by organizing. If revenues are so low that workers' expected gain from unionization is negative even if they are offered $W=0$, one can immediately show that unionization cannot happen in equilibrium. An increase in revenues may raise the probability of unionization in this case if it translates into an increase in union wages large enough to make unionization potentially profitable for workers.

\subsubsection{Unions' bargaining strength}

Unions' bargaining strength is often referred to as a major factor influencing unionization. If we measure the union's bargaining strength by the share of the revenues that the union appropriates for its members, changes in bargaining strength correspond in the model to changes in $W^{u}$. For the same reasons as above, an increase in bargaining strength may increase the probability of unionization for firms in the lower part of the distribution of rents, but there are no a priori reasons to expect an increase in bargaining strength to affect unionization probabilities among unionizable firms. It is worth noting that it also follows from this result that one should be cautious when interpreting union density (the proportion of workers represented by unions) as a measure of unions' bargaining strength.

\subsection{Measurement of union effects}

As discussed in the introduction, one of the main problems facing the empirical literature on the impact of unions is the fact that the union status of firms and workers is likely to be related to firm characteristics that affect performance or wages, yet are unobservable to the econometrician. This may result in biased estimates whose interpretation depends on underlying theories of unionization. For example, it is commonly argued in empirical work that unions are more likely to organize more profitable firms and, therefore, that the estimates of the impact of unionization on profits, which are generally negative, underestimate the true effect of unions. The same reasoning would imply that the union wage premium is overestimated.

The model in this paper has two main implications concerning the measurement of union effects. The first one is that we should indeed expect unionization to be correlated with firm characteristics that are inherently unobservable to the researcher, but that affect wages and firm performance. In particular, the model shows that unionization will be more likely in firms with lower revenues precisely when firms' ability to generate revenues cannot be observed by workers and, thus, probably not by the researcher either. Thus, biases due to underlying differences between union and nonunion firms may not be easy to eliminate. The second implication is that the resulting biases will have a definite sign. Since unionization is more likely in firms that would pay lower wages and generate lower rents, 
standard estimates will underestimate the positive effect of unions on wages and overestimate (in absolute terms) the negative effect of unions on profits. ${ }^{10}$

\subsection{Union wage premium and unionization}

The union wage premium is often attributed a key causal role in the determination of unionization, either by encouraging unionization or employer resistance to it. In the model presented here, however, unionization and the union wage premium are simultaneously determined in equilibrium. As a result, we cannot talk of a causal effect of the wage premium on unionization. We can, however, analyze the joint behavior of the probability of unionization and the estimated wage gap in equilibrium. To do this, suppose that there is a population of ex ante identical firms and that the same equilibrium holds at all firms. With this assumption, we can estimate the union wage premium as $W G=w^{u}-w^{n}$, where $w^{u}$ is the average wage of those firms that become unionized in equilibrium, and $w^{n}$ the average wage of those that remain nonunion. ${ }^{11}$ Assuming for simplicity, as in Section 4.2, that whenever pooling equilibria are possible, $\sigma^{*}\left(W_{p}^{*}\right)=0$, there is unionization in equilibrium only when equilibria are separating. At these equilibria, $\sigma^{*}\left(W_{L}^{*}\right)=$ $\underline{\sigma}$ and $\sigma^{*}\left(W_{H}^{*}\right)=0$. Thus, $w^{u}=w_{L}^{u}$ and, letting $c$ denote the costs of organization per worker,

$$
\begin{aligned}
& w^{n}=\frac{q\left(w_{H}^{u}-c\right)+(1-q)(1-\sigma)\left(w_{L}^{u}-c\right)}{q+(1-q)(1-\sigma)}=\frac{q w_{H}^{u}+(1-q)(1-\sigma) w_{L}^{u}}{q+(1-q)(1-\sigma)}-c \\
& W G=w^{u}-w^{n}=c^{-} \frac{q\left(w_{H}^{u}-w_{L}^{u}\right)}{q+(1-q)(1-\sigma)}
\end{aligned}
$$

Recalling that $\underline{\sigma}$ is decreasing in $c$, it follows that $W G$ is increasing in $c .{ }^{12}$ Since the probability of unionization $((1-q) \sigma)$ is decreasing in $c$, an increase (reduction) in $c$, thus, translates into a lower (higher) probability of unionization and a higher (lower) wage gap. Therefore, change in the costs of organization will induce a negative correlation between the wage gap and the probability of unionization. Inspection of (3) and Corollary 2 shows that changes in $w_{H}^{u}-w_{L}^{u}$ will also induce a negative correlation between unionization and the wage gap.

If the efficiency gains generated by unionization are not related to revenues, then, with complete information, the probability of unionization will be independent of revenues as well. Since in a complete information equilibrium with low- and high-value firms, union firms would pay $w_{i}^{u}$ and nonunion firms $w_{i}^{u}-c(i=L, H)$, the wage gap would be $c$ if the proportion of firms in which unionization is efficient (and which become unionized in equilibrium) is the same for both types. A negative association between the wage premium and the probability of unionization, induced by changes in $c$ is, thus, likely to emerge as well.

It is worth remarking that an implication of the negative correlation between the wage gap and the probability of unionization is that it may be misleading to interpret the wage gap as a measure of unions' ability to organize new establishments.

\footnotetext{
${ }^{10}$ It should be noted, however, that a bias with the conventional sign may emerge if we cannot control for observed profitability and there is a significant fraction of firms that are not unionizable. Those firms can be expected to be less profitable and to pay low wages independently of union status.

${ }^{11}$ The wage gap is defined, as customary, in terms of wages lowercase and not in terms of total wage bills uppercase although, given the assumptions of the model, results would be the same if we looked at the wage bill gap.

12 The wage gap in a separating equilibrium may be small and even negative. This result could help explain the findings of Freeman and Kleiner (1990b) and DiNardo and Lee (2004) that new unionization seems to have no significant effect on wages when comparing similar firms.
} 


\subsection{Empirical evidence}

The model presented in this paper implies that: 1) unionization is not likely to be associated with observable profitability; 2) unionization is more likely in firms with lower unobserved profitability; 3) unionization is more likely where it can provide efficiency gains; 4) unionization is more likely where organization costs are lower; 5) the probability of unionization and the union wage premium are likely to be negatively correlated. These predictions are largely consistent with the available empirical evidence from the U.S., which is the country whose bargaining framework most closely resembles the one in the model. ${ }^{13}$

Regarding the relation of unionization and observed profitability, the only firm-level studies that I am aware of (Bronars and Deere, 1993; Bronfenbrenner, 1997) find either no or negative correlation between firm growth or profitability and new unionization, while no clear picture emerges from more aggregated studies. Not surprisingly, there is no direct evidence on the relationship between unobserved profitability and unionization, since the role of asymmetric information in unionization has not been explored empirically.

With respect to the effect that potential efficiency consequences of unionization have on the probability of organization, there is evidence that unionization is more likely in firms where working conditions make some form of collective organization efficient (Duncan and Stafford, 1980 ) and that unionization tends to be followed by the adoption of grievance and promotion procedures consistent with the governance role of the union (Freeman and Kleiner, 1990b). The evidence on the productivity effects of unions is, however, mixed (Booth, 1995).

The empirical evidence generally supports the predictions that unionization is less likely when costs of organization are higher. In particular, the studies that have analyzed the effect of managerial opposition on unionization generally find a negative effect, although different studies differ in the magnitude of this effect (see e.g., Freeman and Kleiner, 1990a).

Finally, there seems to exist a negative relation between union wage premia and new unionization (Freeman, 1986; Linneman et al., 1990; Bratsberg and Ragan, 2002).

\section{Conclusion}

I have presented a theoretical model of unionization in which firms' union status is derived as the equilibrium outcome of the strategic interaction of optimizing workers and employers. The model shows that unionization will be more likely in those firms in which unions generate efficiency gains, supporting efficiency-based explanations of unionization. In fact, in the absence of informational asymmetries, the effect of unions on surplus, net of the costs of unionization incurred by workers, is the only determinant of unionization. Factors such as firms' profitability or unions' bargaining power do not play any causal role in this context.

The nature of managers' tasks, however, suggests that they are likely to be better informed than workers about their firms' prospects. I have shown that this informational asymmetry may play a key role in determining unionization. When there is asymmetric information, unionization becomes possible even if it is inefficient. Contrary to usual presumptions, however, inefficient unionization is more likely in firms with worse prospects.

\footnotetext{
${ }^{13}$ A full review of the empirical literature on the determinants of union membership is not attempted here. See Schnabel (2003) for a recent review.
} 
In the model, the union wage premium and unionization are determined simultaneously in equilibrium. Since the two variables are likely to move in opposite directions in response to changes in parameter values, the model predicts that they will tend to be negatively correlated. This result is in contrast with the common argument that unionization will be more likely when the wage premium is high because of a greater demand for union services.

In summary, this paper questions some commonly-held assumptions about the impact on unionization of factors such as firm profitability or the union wage premium, highlights the effects of other factors, such as the costs of organization to workers or the efficiency effects of unions, and shows that asymmetries of information between workers and employers may play an important role in explaining unionization.

There are, however, important aspects of unionization that have not been addressed in this paper, or only in reduced form. In particular, the organization process itself has not been analyzed explicitly, which means that the model cannot shed light on the determinants of the costs of organization. Similarly, the paper has focused on a setting in which both unionization and bargaining take place at the firm level. Although this setting characterizes well the U.S. and the British labor markets, more work is required to understand the determinants of unionization in more centralized systems, such as those present in most of continental Europe. Further, by focusing on a single firm, I have not investigated the role of market interactions or of bargaining or organization externalities across firms (emphasized, among others, by Freeman, 1998). I believe, however, that the framework developed here can be profitably extended to analyze these and other aspects of unionization.

\section{Proofs}

Proof of Proposition 1. Let $\sigma_{0}\left(W_{0}\right)$ be the probability of rejecting wage $W_{0}$ in the first period, and $\sigma(W)$ be the probability of unionizing if wage $W$ is offered in the second period.

The result is proven by backward induction. In the last stage, workers' best response is $\sigma^{*}(W)=$ 1 if $W<W^{u}-C ; \sigma^{*}(W)=0$ if $W>W^{u}-C$; and $\sigma(W)^{*} \in[0,1]$ if $W=W^{u}-C$. Therefore, the firm's expected profits, given $\sigma^{*}$, if it offers $W$ in the second period are: $E \Pi\left(W, \sigma^{*}\right)=V^{u}-W^{u}$, if $W<W^{u}-C ; E \Pi\left(W, \sigma^{*}\right)=V-W$, if $W>W^{u}-C$; and $E \Pi\left(W^{u}-C, \sigma^{*}\right)=\sigma^{*}\left(W^{u}-C\right)\left(V^{u}-W^{u}\right)+$ $\left(1-\sigma^{*}\left(W^{u}-C\right)\right)\left(V-W^{u}+C\right)$.

It follows that in any subgame perfect equilibrium, $W^{*} \leq W^{u}-C$, since, if $W^{*}>W^{u}-C$, then for any $W^{\prime} \in\left(W^{u}-C, W^{*}\right), E \Pi\left(W^{\prime}, \sigma^{*}\right)=V-W^{\prime}>V-W^{*}=E \Pi\left(W^{*}, \sigma^{*}\right)$.

Suppose that $V^{u}-V<C$. In this case, $W<W^{u}-C$ cannot be optimal for the firm, since if $W^{\prime}=W^{u}-C+\varepsilon$, then $V^{u}-V<C$ implies that $E \Pi\left(W^{\prime}, \sigma^{*}\right)=V-W^{u}+C-\varepsilon>V^{u}-W^{u}=E \Pi(W$, $\left.\sigma^{*}\right)$ for $\varepsilon>0$ small enough. Therefore, in equilibrium, $W^{*}=W^{u}-C$.

Now, if $\sigma^{*}\left(W^{u}-C\right)>0, V^{u}-V<C$ would again imply that deviating to $W=W^{u}-C+\varepsilon$ would be profitable for the firm for $\varepsilon$ small enough. Thus, in equilibrium, $\sigma^{*}\left(W^{u}-C\right)=0$.

Given $\sigma^{*}$ and $W^{*}$, and assuming that workers' outside option is zero in both periods, it is optimal for workers to accept any $W_{0} \geq-W^{*}$ in the initial period, and, thus, it is also optimal for the firm to offer $W_{0}^{*}=-W^{*}$. As shown above for $\sigma^{*}, \sigma_{0}^{*}\left(-W^{*}\right)>0$ is not possible in equilibrium. Therefore, if $V^{u}-V<C$, the unique subgame perfect equilibrium is: $W_{0}^{*}=-\left(W^{u}-C\right)$ and $W^{*}=W^{u}-C ; \sigma_{0}^{*}\left(W_{0}\right)=0$ if $W_{0} \geq-\left(W^{u}-C\right)$ and $\sigma_{0}^{*}\left(W_{0}\right)=1$ if $W_{0}<-\left(W^{u}-C\right) ; \sigma^{*}(W)=1$ if $W<W^{u}-C ; \sigma^{*}(W)=0$ if $W \geq W^{u}-C$.

Suppose now that $V^{u}-V>C$. Then, for any $W^{\prime} \geq W^{u}-C, E \Pi\left(W^{\prime}, \sigma^{*}\right) \leq V-W^{u}+C<V^{u}-W^{u}$. Therefore, it is optimal for the firm to trigger unionization by offering $W^{* *}<W^{u}-C$. Since workers obtain $W^{u}-C$ in the second period, it follows that $W^{* *}=-\left(W^{u}-C\right)$. 
Proof of Proposition 2. I first describe the conditions that must hold at any equilibrium (separating or pooling) and, then, characterize the set of separating equilibria.

1. Equilibrium strategies in any perfect Bayesian equilibrium (PBE).

Let $E U(W, \rho) \equiv \rho(W) W_{H}^{u}+(1-\rho(W)) W_{L}^{u}-C$. Then, D.1 in Definition 1 implies that: $\sigma^{*}(W)=0$ if $E U(W, \rho)<W ; \sigma^{*}(W)=1$ if $E U(W, \rho)>W$; and $\sigma^{*}(W) \in[0,1]$ if $E U(W, \rho)=W$. Therefore, $\sigma^{*}(W)=0$ for $W>W_{H}^{u}-C$ and $\sigma^{*}(W)=1$ for $W<W_{L}^{u}-C$ for any $\rho$.

Let $W_{i}$ be the wage set by a type- $i$ firm and $E \Pi_{i}(W, \sigma) \equiv \sigma(W)\left(V_{i}^{u}-W_{i}^{u}\right)+(1-\sigma(W))\left(V_{i}-W\right)$ denote the expected profit of a firm of type $i$ if it offers a wage $W$ and workers' strategy is $\sigma$. Let also $\widehat{W}^{i} \equiv W_{i}^{u}+V_{i}-V_{i}^{u}$ denote the wage that guarantees a firm of type $i$ an expected profit $E \Pi_{i}\left(\widehat{W}_{i}\right.$, $\sigma)=V_{i}^{u}-W_{i}^{u}$ independently of $\sigma$. Then, for any $W>\widehat{W}_{i}$ and any $\sigma(W)<1, E \Pi_{i}(W, \sigma)=\sigma(W)$ $\left(V_{i}^{u}-W_{i}^{u}\right)+(1-\sigma(W))\left(V_{i}-W\right)<V_{i}^{u}-W_{i}^{u}=E \prod_{i}\left(\widehat{W}_{i}, \sigma\right)$. Therefore, in equilibrium, D.2 implies that $W_{i}^{*}$ can be greater than $\widehat{W}_{i}$ only if $\sigma^{*}\left(W_{i}^{*}\right)=1$.

Further, $W_{i}^{*}>W_{H}^{u}-C$ is not possible in equilibrium, since any $W^{\prime} \in\left(W_{H}^{u}-C, W_{i}^{*}\right)$ would be a profitable deviation for a firm of type $i$ (since $\sigma^{*}(W)=0$ for any $W>W_{h}^{u}-C$ ). Therefore, in equilibrium, $W_{i}^{*} \leq W_{H}^{u}-C$, for $i=L, H$.

Now, D.2 in Definition 1 requires that for any type $i$ and any $W$ :

$$
\sigma^{*}\left(W_{i}^{*}\right)\left(V_{i}^{u}-W_{i}^{u}\right)+\left(1-\sigma^{*}\left(W_{i}^{*}\right)\right)\left(V_{i}-W_{i}^{*}\right) \geq \sigma^{*}(W)\left(V_{i}^{u}-W_{i}^{u}\right)+\left(1-\sigma^{*}(W)\right)\left(V_{i}-W\right)
$$

If $W_{i}^{*} \leq \widehat{W}_{i}$, then AS.1 ensures that (4) holds for any $W \geq \widehat{W}_{i}$ and any $\sigma^{*}$. It was shown above that $W_{i}^{*}>\widehat{W}_{i}$ is possible only if $\sigma^{*}\left(W_{i}^{*}\right)=1$. Again in this case, AS.1 ensures that (4) holds for any $W \geq \widehat{W}_{i}$ and any $\sigma^{*}(W)$. Therefore, it is never profitable to deviate to $W \geq \widehat{W}_{i}$.

Note that, for $W<\widehat{W}_{i},(4)$ can be rewritten as:

$$
\sigma^{*}(W) \geq \frac{W_{i}^{*}-W+\sigma^{*}\left(W_{i}^{*}\right)\left(\widehat{W}_{i}-W_{i}^{*}\right)}{\widehat{W}_{i}-W} \equiv \sigma_{i}(W), i=L, H .
$$

Next, let $W_{\epsilon}=W_{H}^{u}-C+\epsilon$, with $\epsilon>0$ (and note that AS.1 implies that, for $\epsilon$ small enough $\left.W_{\epsilon}<\widehat{W}_{H}\right)$. Then, since $\sigma^{*}\left(W_{\epsilon}\right)=0$, for (5) to hold at $W_{\epsilon}$, it must be the case that

$$
W_{i}^{*}-\left(W_{H}^{u}-C+\varepsilon\right)+\sigma^{*}\left(W_{i}^{*}\right)\left(\widehat{W} i-W_{i}^{*}\right) \leq 0
$$

This implies that $W_{H}^{*}<\widehat{W}_{H}$, since if $W_{H}^{*} \geq \widehat{W}_{H}$ the left-hand side of the inequality for $i=H$ becomes $\widehat{W}_{H}-\left(W_{H}^{u}-C+\epsilon\right)$ (recall that if $W_{H}^{*}>\widehat{W}_{H}$, then $\left.\sigma^{*}\left(W_{H}^{*}\right)=1\right)$, which, for $\epsilon$ small enough, is positive if AS.1 holds. Now, since (6) must hold for any $\epsilon>0$, then if $W_{i}^{*}<\widehat{W}_{i}$ :

$$
\sigma^{*}\left(W_{i}^{*}\right) \leq \frac{W_{H}^{u}-C-W_{i}^{*}}{\widehat{W}_{i}-W_{i}^{*}}=\frac{W_{H}^{u}-C-W_{i}^{*}}{W_{i}^{u}+V_{i}-V_{i}^{u}-W_{i}^{*}}
$$

Since $W_{H}^{*}<\widehat{W}_{H}$, it follows from this expression and AS.1 that, in any PBE, $\sigma^{*}\left(W_{H}^{*}\right)<1$.

2. Separating equilibria. At a separating equilibrium, $W_{H}^{*} \neq W_{L}^{*}$, so D.3 in Definition 1 implies that $\rho^{*}\left(W_{H}^{*}\right)=1$ and $\rho^{*}\left(W_{L}^{*}\right)=0$. It follows from $\rho^{*}\left(W_{H}^{*}\right)=1$ and $\sigma^{*}\left(W_{H}^{*}\right)<1$ that $W_{H}^{*} \geq W_{H}^{u}-C$. Since we already know that $W_{H}^{*} \leq W_{H}^{u}-C$, then, at any separating equilibrium, $W_{H}^{*}=W_{H}^{u}-C$. Further, substituting $W_{H}^{*}=W_{H}^{u}-C$ into (7):

$$
\sigma^{*}\left(W_{H}^{*}\right) \leq \frac{W_{H}^{u}-C-\left(W_{H}^{u}-C\right)}{W_{H}^{u}+V_{H}-V_{H}^{u}-\left(W_{H}^{u}-C\right)}=0,
$$

so, at any separating equilibrium $\sigma^{*}\left(W_{H}^{*}\right)=0$. 
Next, I check that high-value firms do not want to deviate from $W_{H}^{*}$. From $\sigma^{*}\left(W_{H}^{*}\right)=0$, it follows that $E \Pi_{H}\left(W_{H}^{*}, \sigma^{*}\right)>E \Pi_{H}\left(W, \sigma^{*}\right)$ for any $W>W_{H}^{*}$. Further, AS.1 implies that, for any $W<W_{L}^{u}-C, E \Pi_{H}\left(W_{H}^{*}, \sigma^{*}\right)=V_{H}-W_{H}^{u}+\mathrm{C}>V_{H}^{u}-W_{H}^{u}=E \Pi_{H}\left(W, \sigma^{*}\right)$. So, it only rests to check that (5) holds for $W \in\left[W_{L}^{u}-C, W_{H}^{*}\right)$ :

$$
\sigma^{*}(W) \geq \sigma_{H}(W)=\frac{W_{H}^{*}-W+\sigma^{*}\left(W_{H}^{*}\right)\left(\widehat{W}_{H}-W_{H}^{*}\right)}{\widehat{W}_{H}-W}=\frac{W_{H}^{u}-C-W}{W_{H}^{u}+V_{H}-V_{H}^{u}-W}>0
$$

Now, we know that at any equilibrium $W_{L}^{*} \leq W_{H}^{u}-\mathrm{C}$. Further, since $W_{H}^{*}=W_{H}^{u}-\mathrm{C}$ and the equilibrium is separating, it follows that $W_{L}^{*}<W_{H}^{u}-C$. Therefore, (9) implies that $\sigma^{*}\left(W_{L}^{*}\right)>0$, which requires $W_{L}^{*} \leq \rho^{*}\left(W_{L}^{*}\right)\left(W_{H}^{u}-C\right)+\left(1-\rho^{*}\left(W_{L}^{*}\right)\right)\left(W_{L}^{u}-C\right)=W_{L}^{u}-C$, where the last equality follows from $\rho^{*}\left(W_{L}^{*}\right)=0$. Therefore, $W_{L}^{*} \leq W_{L}^{u}-C$.

I will first analyze equilibria with $W_{L}^{*}=W_{L}^{u}-C$. In this case, it follows from (9) that for a highvalue firm not to deviate and set $W_{L}^{*}$ :

$$
\sigma^{*}\left(W_{L}^{*}\right) \geq \frac{W_{H}^{u}-W_{L}^{u}}{W_{H}^{u}-W_{L}^{u}+V_{H}-V_{H}^{u}+C} \equiv \sigma
$$

Next, I check that low-value firms do not want to deviate from $W_{L}^{*}$. It was shown above that deviating to $W \geq \widehat{W}_{L}$ can never be profitable. Similarly, $\sigma^{*}(W)=1$ for $W<W_{L}^{u}-C$ implies that deviations to $W<W_{L}^{u}-C$ are not profitable. Thus, it only rests to check (5):

$$
\sigma^{*}(W) \geq \sigma_{L}(W)=\frac{W_{L}^{u}-C-W+\sigma^{*}\left(W_{L}^{*}\right)\left(V_{L}-V_{L}^{u}+C\right)}{W_{L}^{u}+V_{L}-V_{L}^{u}-W}, \text { for } W \in\left(W_{L}^{u}-C, \widehat{W}_{L}\right)
$$

If $W_{H}^{*} \leq \widehat{W}_{L}, \sigma^{*}\left(W_{H}^{*}\right) \geq \sigma_{L}\left(W_{H}^{*}\right)$ and $\sigma^{*}\left(W_{H}^{*}\right)=0$ imply that $\sigma_{L}\left(W_{H}^{*}\right) \leq 0$ and, thus, that:

$$
\sigma^{*}\left(W_{L}^{*}\right) \leq \frac{W_{H}^{u}-C-W_{L}^{*}}{W_{L}^{u}+V_{L}-V_{L}^{u}-W_{L}^{*}}=\frac{W_{H}^{u}-W_{L}^{u}}{V_{L}-V_{L}^{u}+C} \equiv \sigma
$$

Therefore, if $W_{H}^{*} \leq \widehat{W}_{L},(10)$ and (12) imply that $\sigma \leq \sigma^{*}\left(W_{L}^{*}\right) \leq \sigma$. Hence, if $W_{H}^{*} \leq \widehat{W}_{L}$, a separating equilibrium can exist only if $\sigma \leq \sigma$, which holds if and only if:

$$
W_{H}^{u}-W_{L}^{u}+V_{H}-V_{H}^{u}+C \geq V_{L}-V_{L}^{u}+C,
$$

which is just assumption AS.2 (and can be rewritten $\widehat{W}_{H} \geq \widehat{W}_{L}$ ). Further, if $W_{H}^{*}>\widehat{W}_{L}$, then AS.1 implies AS.2. Therefore, AS.2 must hold at any separating equilibrium.

Equilibria with $W_{L}^{*}<W_{L}^{u}-C$ require $\sigma^{*}\left(W_{L}^{*}\right)=1$. Therefore, at these equilibria, $W_{L}^{*}$ is not a profitable deviation for a high-value firm. Further, since $\sigma^{*}\left(W_{L}^{*}\right)=1$ implies that $\sigma_{L}(W)=1$ for $W<\widehat{W}_{L}-C$ (from (11)), (5) requires that $\sigma^{*}(W)=1$ for $W<\widehat{W}_{L}$. Therefore, if $W_{H}^{*}<\widehat{W}_{L}$, equilibria with $W_{L}^{*}<W_{L}^{u}-C$ are not possible, since $\sigma^{*}\left(W_{H}^{*}\right)=0$. If $W_{H}^{*} \geq \widehat{W}_{L}$, however, these equilibria are possible as long as $\sigma^{*}(W)=1$ for $W<\widehat{W}_{L}$, and (9) holds for $W \in\left[\widehat{W}_{L}, W_{H}^{*}\right)$.

Finally, note that for $\sigma^{*}(W)>0$ to be optimal for workers for any $W \in\left(W_{L}^{u}-C, W_{H}^{u}-C\right)$, it has to be the case that $\rho^{*}(W) W_{H}^{u}+\left(1-\rho^{*}(W)\right) W_{L}^{u}-C \geq W$, that is,

$$
\rho^{*}(W) \geq \frac{W-W_{L}^{u}+C}{W_{H}^{u}-W_{L}^{u}} \equiv \rho_{m}(W)
$$


It follows that:

1. If AS.2 does not hold, $\sigma>\sigma$ and $W_{H}^{u}-C<\widehat{W}_{L}$, so there are no separating equilibria.

2. If AS.2 holds, then $\left[\sigma^{*},\left(W_{L}^{*}, W_{H}^{*}\right), \rho^{*}\right]$ is a PBE if: i) $W_{L}^{*}=W_{L}^{u}-C$ and $W_{H}^{*}=W_{H}^{u}-C$; ii) $\sigma^{*}(W)=0$ for $W \geq W_{H}^{*}, \sigma^{*}(W)=1$ for $W<W_{L}^{*}, \sigma^{*}\left(W_{L}^{*}\right) \in[\sigma, \min \{1, \sigma\}]$, and $\sigma^{*}$ $(W) \geq \max \left\{\sigma_{L}(\mathrm{~W}), \sigma_{H}(W)\right\}$ otherwise; iii) $\rho^{*}\left(W_{L}^{*}\right)=0, \rho^{*}\left(W_{H}^{*}\right)=1, \rho^{*}(W) \geq \rho_{m}(W)$ for $W \in\left(W_{L}^{*}, W_{H}^{*}\right)$ (with $\rho^{*}(W)=\rho_{m}(W)$ if $\sigma^{*}(W)<1$ ), and $\rho^{*}(W) \in[0,1]$ otherwise.

3. If AS.2 and $W_{H}^{u}-C<\widehat{W}_{L}$, there are no separating equilibria other than the ones described above. If $W_{H}^{u}-C \geq \widehat{W}_{L}$, there are also separating equilibria with: i) $W_{L}^{*}<W_{L}^{u}-C, W_{H}^{*}=W_{H}^{u}-C$; ii) $\sigma^{*}$ $(W)=1$ for $W<\widehat{W}_{L}, \sigma^{*}(W) \geq \sigma_{H}(W)$, for $W \in\left[\widehat{W}_{L}, W_{H}^{*}\right)$ and $\sigma^{*}(W)=0$ for $W \geq W_{H}^{*}$; iii) $\rho^{*}\left(W_{L}^{*}\right)=0, \rho^{*}\left(W_{H}^{*}\right)=1, \rho^{*}(W) \geq \rho_{m}(W)$ for $\mathrm{W} \in\left[W_{L}^{u}-C, W_{H}^{*}\right)\left(\right.$ with $\rho^{*}(W)=\rho_{m}$ $(W)$ if $\left.\sigma^{*}(W)<1\right)$, and $\rho^{*}(W) \in[0,1]$ otherwise.

Proof of Proposition 3. At a pooling equilibrium, $W_{L}^{*}=W_{H}^{*}=W_{p}^{*}$, so it follows from $\sigma^{*}\left(W_{H}^{*}\right)<1$ (see inequality (7)) that $\sigma^{*}\left(W_{p}^{*}\right)<1$, which implies that $W_{p}^{*} \leq \min \left\{\widehat{W}_{L}, \widehat{W}_{H}\right\}$ (since $W_{i}^{*}>\widehat{W}_{i}$ is possible only if $\sigma^{*}\left(W_{i}^{*}\right)=1$. Since we know that in equilibrium $W_{i}^{*} \leq W_{H}^{u}-\mathrm{C}$, it follows that $W_{p}^{*} \leq \min \left\{\widehat{W}_{L}, \widehat{W}_{H}, W_{H}^{u}-\mathrm{C}\right\}$. Further, $\sigma^{*}\left(W_{p}^{*}\right)<1$ requires $E U\left(W_{p}^{*}, \rho^{*}\right) \leq W_{p}^{*}$. Since D.3 requires $\rho^{*}\left(W_{p}^{*}\right)=q$, this last inequality becomes $\mathrm{q} W_{H}^{u}+(1-\mathrm{q}) W_{L}^{u}-C \equiv W_{p} \leq W_{p}^{*}$. Therefore, a necessary condition for a pooling equilibrium to exist is $W_{p} \leq \min \left\{\widehat{W}_{\mathrm{L}}, \widehat{W}_{\mathrm{H}}, W_{H}^{u}-C\right\}$. Since $W_{p}<W_{H}^{u}-C$, and AS.1 implies $W_{H}^{u}-C<\widehat{W}_{H}$, this condition will hold if and only if $W_{p} \leq \widehat{W}_{L}$, which, rearranging, becomes condition (1):

$$
V_{L}-\left(q W_{H}^{u}+(1-q) W_{L}^{u}-C\right) \geq V_{L}^{u}-W_{L}^{u}
$$

Note that if $\widehat{W}_{L}>\widehat{W}_{H}$, that is, if AS.2 does not hold, then $W_{p} \leq \widehat{W}_{L}$, since $W_{p}<W_{H}^{u}-\mathrm{C}<\widehat{W}_{H}$. Thus, if $\widehat{W}_{L}>\widehat{W}_{H}$, then (1) holds.

. If $W_{L}^{*}=W_{H}^{*}=W_{p}^{*}, \sigma_{L}$ and $\sigma_{L}$, defined in the no-deviation condition (5), become:

$$
\sigma_{i}(W)=\frac{W_{p}^{*}-W+\sigma^{*}\left(W_{p}^{*}\right)\left(\widehat{W}_{i}-W_{p}^{*}\right)}{\widehat{W}_{i}-W}, \text { for any } W \leq \widehat{W}_{i} ; i=L, H \text {. }
$$

Therefore, if $\widehat{W}_{H}>\widehat{W}_{L}$ (i.e., if AS.2 holds), $\sigma_{L}(W)>\sigma_{H}(W)$ for $W<W_{p}^{*}$, and $\sigma_{L}(W)<\sigma_{H}(W)$ for $W>W_{p}^{*}$. If $\widehat{W}_{H}<\widehat{W}_{L}$ (i.e., if AS.2 does not hold), the inequalities are reversed.

1. Suppose first that AS.2 holds $\left(\widehat{W}_{L}<\widehat{W}_{H}\right)$. If (1) does not hold, there are no pooling equilibria. If (1) holds, then, to guarantee that no firm type wants to deviate to $W<W_{p}^{*}$, it suffices to check that $\sigma^{*}(W) \geq \sigma_{L}(W)$. For $W \in\left(W_{p}^{*}, W_{H}^{u}-C\right]$, it suffices to check that $\sigma^{*}(W) \geq \sigma_{H}(W)$. Finally, for no wage $W>W_{H}^{u}-C$ to be a profitable deviation, condition (7) must hold for both firm types. Since $\widehat{W}_{L} \leq \widehat{W}_{H}$, it suffices to check that:

$$
\sigma^{*}\left(W_{p}^{*}\right) \leq \frac{W_{H}^{u}-C-W_{p}^{*}}{\widehat{W}_{H}-W_{p}^{*}}=\frac{W_{H}^{u}-C-W_{p}^{*}}{W_{H}^{u}+V_{H}-V_{H}^{u}-W_{p}^{*}} \equiv \sigma_{1},
$$

where $\sigma_{1}<1$ because of AS.1.

Thus, if AS.2 and (1) hold, [ $\left.\sigma^{*},\left(W_{p}^{*}, W_{p}^{*}\right), \rho^{*}\right]$ is a PBE if and only if: i) $W_{p} \leq W_{p}^{*} \leq \min \left\{\widehat{W}_{L}\right.$, $\left.\mathrm{W}_{H}^{u}-C\right\}$; ii) $\sigma^{*}(W)=0$ for $W>W_{H}^{u}-C, \sigma^{*}(W)=1$ for $W<W_{L}^{u}-C, \sigma^{*}\left(W_{p}^{*}\right)=0$ if $W_{p}^{*}>W_{p}$ and $\sigma^{*}\left(W_{p}^{*}\right) \in\left[0, \sigma_{1}\right]$ if $W_{p}^{*}=W_{p}, \sigma^{*}(W) \geq \sigma_{L}(W)$ for $W \in\left[W_{L}^{u}-C, W_{p}^{*}\right)$, and $\sigma^{*}(W) \geq \sigma_{H}(W)$ for $W \in\left(W_{p}^{*}, W_{H}^{u}-C\right]$; iii) $\rho^{*}\left(W_{p}^{*}\right)=q, \rho^{*}(W) \geq \rho_{m}(W)$ for $W \in\left(W_{L}^{u}-C, W_{H}^{u}-C\right)$, and $\rho^{*}$ $(W) \in[0,1]$ otherwise, for $\rho_{m}$ defined in (14) (with $\rho^{*}(W)=\rho_{m}(W)$ if $\left.\sigma^{*}(W)<1\right)$.

2. Suppose now that AS. 2 does not hold (i.e., $\widehat{W}_{L}>\widehat{W}_{H}$ ). Then, it was shown above that (1) holds. To guarantee that there are no profitable deviations for either type of firm, it now suffices to 
check that, for $W<W_{p}^{*}, \sigma^{*}(W) \geq \sigma_{H}(W)$ and, for $W \in\left(W_{p}^{*}, W_{H}^{u}-C\right], \sigma^{*}(W) \geq \sigma_{L}(W)$. To guarantee that no wage $W>W_{H}^{u}-C$ can be a profitable deviation, $\hat{W}_{L}>\hat{W}_{H}$ implies that we only need to check that condition (7) holds for low-value firms:

$$
\sigma^{*}\left(W_{p}^{*}\right) \leq \frac{W_{H}^{u}-C-W_{p}^{*}}{\widehat{W}_{L}-W_{p}^{*}}=\frac{W_{H}^{u}-C-W_{p}^{*}}{W_{L}^{u}+V_{L}-V_{L}^{u}-W_{p}^{*}} \equiv \sigma_{2}
$$

Therefore, if AS.2 does not hold, $\left[\sigma^{*},\left(W_{p}^{*}, W_{p}^{*}\right), \rho^{*}\right]$ is a PBE if and only if: i) $W_{p}^{*} \in\left[W_{p}\right.$, $\left.W_{H}^{u}-C\right]$; ii) $\sigma^{*}(W)=0$ for $W>W_{H}^{u}-C, \sigma^{*}(W)=1$ for $W<W_{L}^{u}-C, \sigma\left(W_{p}^{*}\right)=0$ if $W_{p}^{*}>W_{p}$ and $\sigma^{*}\left(W_{p}^{*}\right) \in\left[0, \sigma_{2}\right]$ if $W_{p}^{*}=W_{p}, \sigma^{*}(W) \geq \sigma_{H}(W)$ for $W \in\left[W_{L}^{u}-C, W_{p}^{*}\right)$, and $\sigma^{*}(W) \geq \sigma_{L}(W)$ for $W \in\left(W_{p}^{*}, W_{H}^{u}-C\right]$; iii) $\rho^{*}\left(W_{p}^{*}\right)=q ; \rho^{*}(W) \geq \rho_{m}(W)$ for $W \in\left(W_{L}^{u}-C, W_{H}^{u}-C\right.$ ) (with $\rho^{*}$ $(W)=\rho_{m}(W)$ if $\left.\sigma^{*}(W)<1\right)$, and $\rho^{*}(W) \in[0,1]$, otherwise.

Note that if $W_{p}^{*}>W_{p}$, then it must be the case that, for $W^{\prime} \in\left(W_{p}, W_{p}^{*}\right), \rho^{*}\left(W^{\prime}\right)>\rho^{*}\left(W_{p}^{*}\right)=q$. To see this, notice that if $\rho\left(W^{\prime}\right) \leq q$, then $\sigma^{*}\left(W^{\prime}\right)=0$ (since $W^{\prime}>W_{p}$ ), so $W^{\prime}$ would be a profitable deviation.

\section{References}

Booth, A., 1985. The free rider problem and a social custom model of trade union membership. Quarterly Journal of Economics 100 (1), 253261.

Booth, A.L., 1995. The Economics of the Trade Union. Cambridge University Press, Cambridge, U.K.

Bratsberg, B., Ragan, J.F., 2002. Changes in the union wage premium by industry. Industrial and Labor Relations Review $56(1), 6583$.

Bronars, S.G., Deere, D.R., 1993. Union organizing activity, firm growth and the business cycle. American Economic Review 83 (1), 203220.

Bronfenbrenner, K., 1997. The role of union strategies in NLRB certification elections. Industrial and Labor Relations Review 50 (2), 195212.

Corneo, G., 1995. Social custom, management opposition, and trade union membership. European Economic Review 39 (2), 275292.

Corneo, G., Lucifora, C., 1997. Wage formation under union threat effects: Theory and empirical evidence. Labour Economics 4 (1), 265292.

DiNardo, J., Lee, D.S., 2004. Economic impacts of new unionization on private sector employers: 1984 2001. The Quarterly Journal of Economics 119 (4), 13831441.

Duncan, G.J., Stafford, F.P., 1980. Do union members receive compensating wage differentials? American Economic Review 70 (3), 355371.

Farber, H.S., 1990. The decline in unionism in the united states: What can be learned from recent experience. Journal of Labor Economics 8 (1), S75 S105.

Farber, H.S., 2005. Nonunion wage rates and the threat of unionization. Industrial and Labor Relations Review 58 (3), 335352.

Freeman, R.B., 1986. The effect of the union wage differential on management opposition and union organizing success. American Economic Review 76 (2), 9296.

Freeman, R.B., 1998. Spurts in union growth: Defining moments and social processes. In: Bordo, M.D., Goldin, C., White, E.N. (Eds.), The Defining Moment: the Great Depression and the American Economy in the Twentieth Century. The Univ. of Chicago Press, Chicago, IL.

Freeman, R.B., Kleiner, M.M., 1990a. Employer behavior in the face of union organizing drives. Industrial and Labor Relations Review 43 (4), 351365.

Freeman, R.B., Kleiner, M.M., 1990b. The impact of new unionization on wages and working conditions. Journal of Labor Economics 8 (1), S8 S25.

Freeman, R.B., Medoff, J.L., 1984. What Do Unions Do? Basic Books, New York.

Fudenberg, D., Tirole, J., 1991. Game Theory. MIT Press, Cambridge, MA.

Horn, H., Wolinsky, A., 1988. Worker substitutability and patterns of unionisation. The Economic Journal 98 (391), 484497.

Kennan, J., Wilson, R., 1993. Bargaining with private information. Journal of Economic Literature 31 (1), 45104.

Lazear, E., 1983. A competitive theory of monopoly unionism. American Economic Review 73 (4), 631643.

Linneman, P., Wachter, M.L., Carter, W.H., 1990. Evaluating the evidence on union employment and wages. Industrial and Labor Relations Review 44 (1), 3453. 
Naylor, R., Cripps, M., 1993. An economic theory of the open shop trade union. European Economic Review 37 (8), 15991620. Naylor, R., Raaum, O., 1993. The open shop union, wages, and management opposition. Oxford Economic Papers 45 (4), 589604.

Schnabel, C., 2003. Determinants of trade union membership. In: Addison, J.T., Schnabel, C. (Eds.), International Handbook of Trade Unions. Edward Elgar, Cheltenham, UK, pp. 1343.

Williamson, O.E., 1985. The Economic Institutions of Capitalism. Free Press, New York. 